University of Wollongong

Research Online

Faculty of Informatics - Papers (Archive)

Faculty of Engineering and Information

Sciences

$1-1-2007$

\title{
RFID-based anti-theft auto security system with an immobilizer
}

Geeth Jayendra

University of Moratuwa

Sisil kumarawadu

University of Moratuwa

Lasantha Meegahapola

University of Moratuwa, lasantha.meegahapola@rmit.edu.au

Follow this and additional works at: https://ro.uow.edu.au/infopapers

Part of the Physical Sciences and Mathematics Commons

\section{Recommended Citation}

Jayendra, Geeth; kumarawadu, Sisil; and Meegahapola, Lasantha: RFID-based anti-theft auto security system with an immobilizer 2007, 441-446.

https://ro.uow.edu.au/infopapers/1961

Research Online is the open access institutional repository for the University of Wollongong. For further information contact the UOW Library: research-pubs@uow.edu.au 


\title{
RFID-based anti-theft auto security system with an immobilizer
}

\begin{abstract}
This paper presents a novel radio frequency identification (RFID) based vehicle immobilizer system, which features low hacking probability while preserving the safety of the passengers of the hijacked vehicle. The immobilizer uses the active RFID technology where the tag is generated with comparatively large character sets. The receiving unit is intelligently integrated into three control circuits in the vehicle, namely, ignition circuit, power control unit, and automatic gear changing system, enabling it to bring the vehicle speed down to zero in a safe step by step manner. The anti-theft auto security system proposed here was tested under different weather conditions and possible signal distortion situations to verify its reliability.
\end{abstract}

Keywords

theft, immobilizer, system, security, auto, anti, rfid

Disciplines

Physical Sciences and Mathematics

Publication Details

Jayendra, G., kumarawadu, S. \& Meegahapola, L. (2007). RFID-based anti-theft auto security system with an immobilizer. Conference Proceedings - 2nd International Conference on Industrial and Information Systems 2007 (pp. 441-446). USA: IEEE. 


\title{
RFID-Based Anti-theft Auto Security System with an Immobilizer
}

\author{
Geeth Jayendra $^{1}$, Sisil Kumarawadu ${ }^{2}$ and Lasantha Meegahapola ${ }^{3}$ \\ Department of Electrical Engineering, Faculty of Engineering, University of Moratuwa, Sri Lanka \\ ${ }^{1}$ geeth@elect.mrt.ac.lk, ${ }^{2}$ sisil@elect.mrt.ac.lk, ${ }^{3}$ lasantha@elect.mrt.ac.lk
}

\begin{abstract}
This paper presents a novel radio frequency identification (RFID) based vehicle immobilizer system, which features low hacking probability while preserving the safety of the passengers of the hijacked vehicle. The immobilizer uses the active RFID technology where the tag is generated with comparatively large character sets. The receiving unit is intelligently integrated into three control circuits in the vehicle, namely, ignition circuit, power control unit, and automatic gear changing system, enabling it to bring the vehicle speed down to zero in a safe step by step manner. The anti-theft auto security system proposed here was tested under different weather conditions and possible signal distortion situations to verify its reliability.
\end{abstract}

Keywords: - Active RFID, hacking probability, vehicle immobilizer

\section{INTRODUCTION}

Vehicle hijacking has become an ever increasing problem during the last decade and various auto manufactures and researchers have developed and implemented a range of anti-theft security systems to evade hijacking of vehicles. The passive RFID [1], touch sensitive alarms [2], cellular based devices [3],[4],[5], global position system (GPS) tracking devices [6] and voice recognition devices [7] are some of the common technologies which are used in such systems. Passive RFID devices work on their self generated tag, which could be easily hacked by RF tuning devices. Therefore, the vulnerability of hacking of such devices is so high and eventually it does not give any protection at all. Touch sensitive alarm systems could also be disabled by using appropriate gloves like enclosing cloths for human body parts. GPS tracking devices can also be used but it needs extra infrastructure and costly devices to be installed, which make vehicle owners impassive on such devices. GSM devices too have the same problems of costly infrastructure and installment fee.

Even though the existing technologies are capable to track or immobilize the hijacked vehicle they tend to display some drawbacks in terms of cost and conceptual weaknesses like threat to vehicle owner's life. Further, during the last decade, vehicle hijackers are intelligent enough to hack those systems to succeed on their hijacking process. As an example, GPS tracking device could be removed from the vehicle without much effort and could be inserted to another moving vehicle to mislead the trackers.

The concept presented in this paper is novel in terms of the generated tag, reliability, less effect on human factor, and wider interfacing intelligence in terms of vehicle immobilizing action compared with the other vehicle security systems exist today. The main technology behind this system is active RFID, which has the capability of delivering a unique tag with very low hacking probability. Besides, the design can be realized with relative ease at low costs to drive the vehicle hijackers to ambiguity and ultimately get trapped without any hazard to the vehicle owner.

The rest of the paper is organized as follows. Section II describes the basic operating structure of the system. The RFID based Tag Generation is described in section III. Section IV focuses on data identification and processing system and section $\mathrm{V}$ discusses the intelligent vehicle interfacing part. The Field test and discussion is included in section VI. Section VII concludes the paper.

\section{The BASIC OPERATING StRUCtURE OF THE SyStem}

The intelligent immobilizing system basically consists of transmitting unit, receiving unit, and intelligent vehicle interfacing unit. The data receiver is embedded to intelligent vehicle control system whereas transmitter unit is kept with the vehicle owner. This enables an active communication path between the vehicle and the owner (or driver), as long as the two ends are within the operating range of $200 \mathrm{~m}$. Unlike the other security systems, which are embedded with the vehicle key [1], in this system there is relatively high probability of misleading the hijackers also enabling the vehicle owner to immobilize the vehicle within a safer distance. Although this could be implemented using a GPS or cellular system, still the system hacking probability is high as well as the cost. The basic operating structure of the immobilizer is shown in Fig.1.

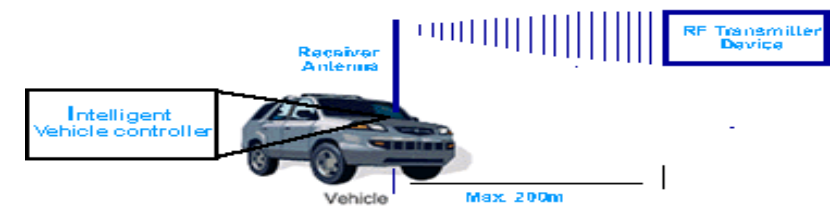

Fig. 1 Basic operating structure of the immobilizing system 
At one single press of the disabling button, the transmitter transmits a unique tag, which is captured and recovered by the receiving system at the vehicle. The tag is identified by the receiver microcontroller using its special data recovery algorithm. Then, suitable disabling signals will be generated to bring down the vehicle speed to zero in step by step manner. The one of the key design features is that, when vehicle is immobilized using this tag system, the vehicle can be restarted only by the transmitting unit's enabling button.

\section{A. Transmitting Unit}

The transmitting unit consists of radio frequency (RF) transmitting module (TRXQ1) [8], Microchip PIC microcontroller (PIC 16F84), enable and disable switches, and battery unit. This is designed to be comparatively smaller and lighter and to be conveniently portable under any contingent situation.

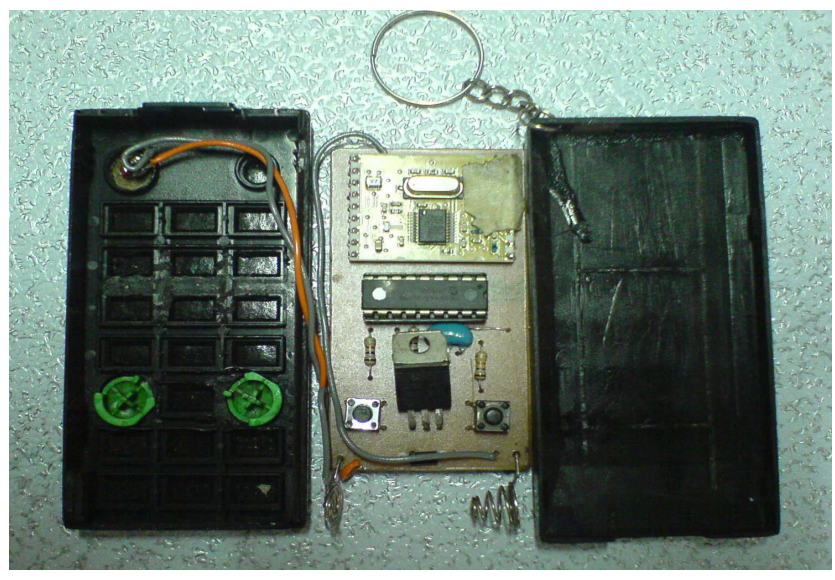

Fig. 2. Transmitting unit

The microcontroller generates and encodes the particular tag that is transmitted to the receiving unit at the vehicle. The tag carries the information of activation or deactivation of the intelligent vehicle control system to immobilize or restart the vehicle. At one enabling or disabling instance, the transmitting unit sends the corresponding unique tag seven times, where the strategy will be described shortly. The functional block diagram of the transmitting unit is given in Fig. 2.

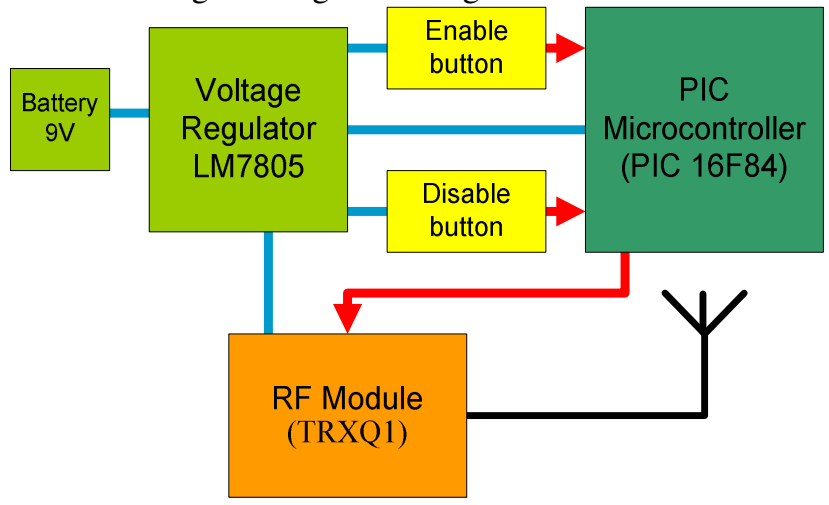

Fig. 3. Transmitting unit functional block diagram

\section{B. Receiving Unit}

The receiving unit, which is continuously operating at data capturing mode to capture the unique tag from the transmitting unit, which consists of a PIC 16F84 microcontroller, RF receiving module (RXQ1) [8], and a regulator circuit. The microcontroller is driven by a special tag recognition algorithm, delivers a special signal to intelligent vehicle control system which is embedded to vehicle ignition unit, vehicle power unit, and the automatic gear changing system. Depending on the vehicle owner's requirements, the number of disabling functions can be embedded to intelligent vehicle control system could be increased. The functional block diagram of the unit is shown in Fig.3.

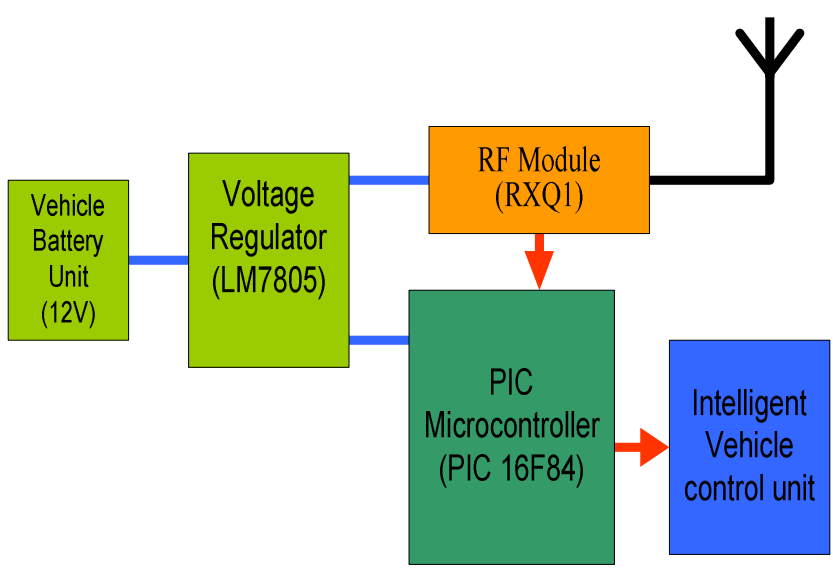

Fig. 4. Receiving Unit functional block diagram

\section{RF Communication Modules}

The data transmission and acquisition system basically consists of frequency modulated (FM) low-power radio communication units [8], where TRXQ1 and RXQ1 (see Fig. 5) are the transmitting and receiving modules used for the wireless communications link between the vehicle and the owner. Under standard operating conditions, they can operate within a range of 0 to $200 \mathrm{~m}$.

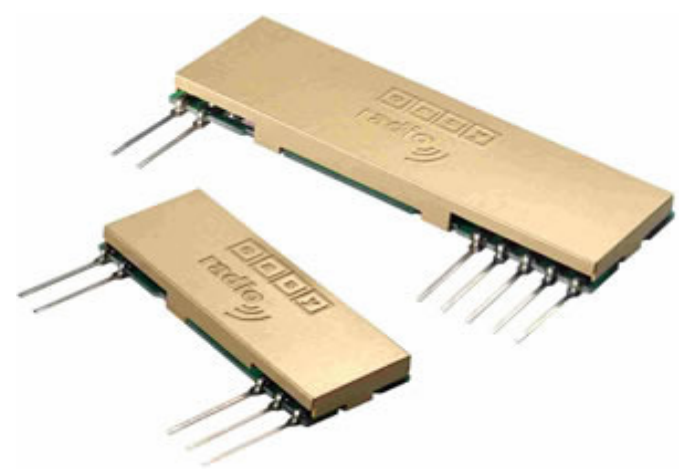

Fig. 5. TRXQ1 and RXQ1 RF module 
The technical specifications of the units are given in Table I.

TABLE 1

THE TECHNICAL SPECIFICATIONS OF WIRELESS MODULES

\begin{tabular}{|c|c|}
\hline Working frequency & $433.92 / 434.33 \mathrm{MHz}$ \\
\hline Receiver sensitivity & $-100 \mathrm{dBm}$ \\
\hline RF power out (transmitter) & $5 \mathrm{dBm}$ \\
\hline FM deviation & $+/-15 \mathrm{kHz}$ \\
\hline Bandwidth & $65-85 \mathrm{kHz}$ \\
\hline Operating temperature & $\begin{array}{c}\text { Minimum }-20^{\circ} \mathrm{C} \\
\text { Maximum }+70^{\circ} \mathrm{C}\end{array}$ \\
\hline Data bit rate & $\begin{array}{c}\text { Minimum } 20 \mathrm{bps} \\
\text { Maximum } 20000 \mathrm{bps}\end{array}$ \\
\hline
\end{tabular}

\section{RFID-BASED TAG GENERATION}

RFID technology was first used during World War II [9], to differentiate between friend and foe aircrafts, and it was emerged in the commercial sector in the 1970s to track products as they moved through the manufacturing process [10], [11]. The most common applications of the RFID technology today are passports [10], product tracking [11], transport payments [10], animal identification systems [13] etc.

\section{A. RFID Operating Principle}

An RFID system consists of three basic components, namely, reader/programmer, antenna and tag or transponder [14] (See Fig 4). The air interface provides the path for active communication between the transmitter and the receiver.

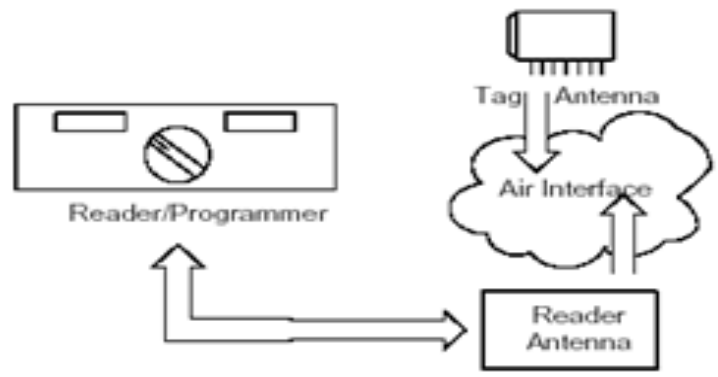

Fig. 6. Basic Components of RFID System

Basically, RFID technology available in two different types, namely, passive RFID and active RFID.

\section{1) Passive Vs Active RFID Systems}

Passive RFID tags have no internal power supply [9]. The electrical current induced in the antenna by the incoming radio frequency signal provides just enough power for the complementary metal-oxide semiconductor (CMOS) integrated circuit in the tag to power up and transmit a response. Most passive tags send the signal by backscattering the carrier signal from the reader. This means that the antenna has to be designed to collect power from the incoming signal and also to transmit the outbound backscatter signal. The response of a passive RFID tag is not necessarily just an ID number, the tag chip can contain non-volatile electronically erasable and programmable ROM (EEPROM) for storing data. Lack of an onboard power supply means that the device can be quite small. In commercially available products, the low frequency RFID tags are embedded to a sticker, or under the skin of the case. Fig. 5 (a) indicates passive RFID system.

Unlike passive RFID tags, active RFID tags have their own internal power source, which is used to power any integrated circuits [9]. Active tags are typically much more reliable (e.g. fewer errors) than passive tags. The active tags, due to their onboard power supply, transmit at higher power levels than passive tags, allowing them to be more effective in "RF challenged" environments like water (including humans/cattle, which are mostly water), metal (shipping containers, vehicles), and most importantly at longer distances. Many active tags have practical range of hundreds of meters, and a battery life of up to 10 years. Fig 5 (b) indicates an active RFID system.

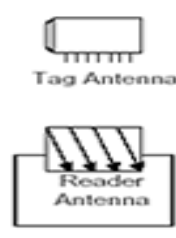

(a)

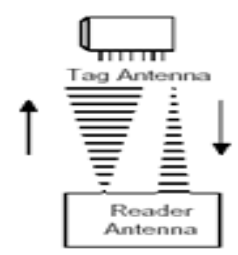

(b)
Fig. 7. Passive and Active RFID Systems

In this approach, an active RFID based system is used, which is equipped with a battery that can be used as a partial or complete source of power for the tag's circuitry and antenna. It possesses the important advantages like longest communication range of any tag, the capability to perform independent monitoring and control, the capability of initiating communications, the capability of performing diagnostics, and the highest data bandwidth. The active RFID tags may even be equipped with autonomous networking therein the tags autonomously determine the best communication path.

\section{B. Tag Characteristics}

The term tag refers to the special security code sent by the transmitting unit, which basically consists of six 8-bit characters. The characters are sent serially through RF communication link to the receiving unit where receiving unit captures the characters serially and checks the validity of the code to enable or disable the intelligent vehicle control system. 
The $n$ is an 8-bit character which could have upto 255 character types. The different combinations $(S)$ possible through the tag are given by

$S=n \times(n-1) \times(n-2) \times(n-3) \times(n-4) \times 1$

The above code is consisted of six characters, where last and final characters should be same for the synchronizing purposes of both the transmitting and receiving unit. The initial character of the generated tag can have $n$ possible values and successive characters can have 1 value less than the previous character to avoid the duplication. Therefore, the hacking probability $(\mathrm{p}(h))$ of the system is given by

$p(h)=\frac{1}{n \times(n-1) \times(n-2) \times(n-3) \times(n-4) \times 1}$

The hacking probability of this system is of the order of $10^{-14}$ and, under any condition, hacking of this system is significantly difficult compared to other systems.

\section{DATA IDENTIFICATION AND PROCESSING SYSTEM}

The data identification and processing is carried out at the receiving end microcontroller, where special algorithm is used to detect the code more accurately. Once the signal is transmitted by the transmitter there is a possibility of delivering a distorted tag at the first cycle of the transmission. Therefore, the tag will be sent seven times at one switching instance. The receiving end identification algorithm is capable of correctly identifying the code under practically encountered distortion conditions.

Initially, at the receiving end, each and every 8-bit character will be assigned to five variables (since first and last character of the tag is the same) in chronological order. Once the data has been received from the transmitting unit, at each and every receiving cycle, the validity of the code will be checked through the assigned variables in chronological order and once they indicate the correct character list in chronological order, the necessary disable or enable signals will be sent by the microcontroller to the intelligent vehicle control unit. The flow chart in Fig. 8 indicates the basic functionality of the receiving end microcontroller algorithm.

In most of the RFID-based systems, there is a possibility of loosing tag characters of the first tag sent by the receiving unit. Under such situations, the receiving end should have the capability of identifying the corrupted tag correctly in order to respond correctly. The approach that we present in this paper has the vital capability of remedying the corrupted tags since transmitting unit sends seven tags simultaneously to the receiving unit at one button press by the user.

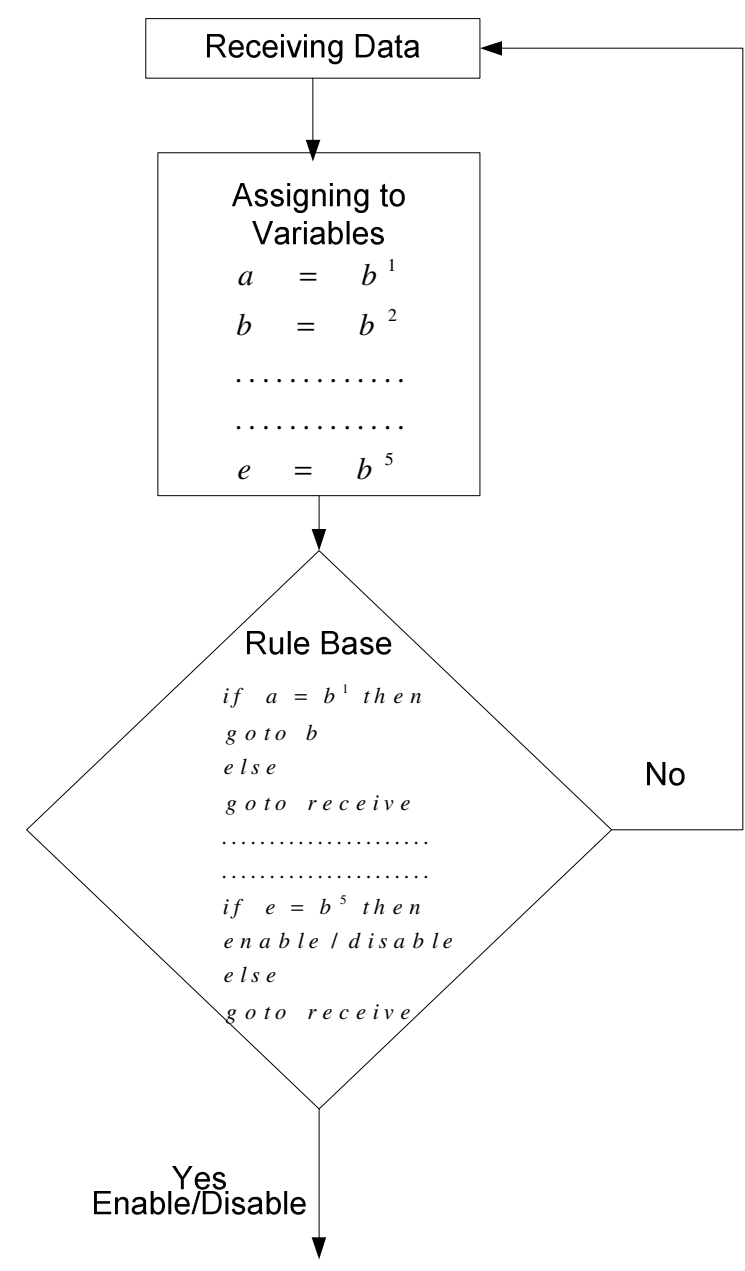

Fig. 8. Flow chart of the tag identification algorithm

To further elaborate, assume that, the sending tag is $b^{1} b^{2} b^{3} b^{4} b^{5} b^{1}$, and the first character of the first tag sent by the transmitting unit is lost. The correct identification of the tag under such a situation is described in Table II.

TABLE 11

DATA IDENTIFICATION WHEN ONE CHARACTER IS MISSING

\begin{tabular}{|c|c|c|}
\hline \multirow{2}{*}{$\begin{array}{c}\text { Assigned } \\
\text { Variable }\end{array}$} & \multicolumn{2}{|c|}{ Receiving cycle } \\
\cline { 2 - 3 } & 1 & 2 \\
\hline$a$ & $\mathrm{~b}^{2}$ & $\mathrm{~b}^{1}$ \\
\hline$b$ & $\mathrm{~b}^{3}$ & $\mathrm{~b}^{2}$ \\
\hline$c$ & $\mathrm{~b}^{4}$ & $\mathrm{~b}^{3}$ \\
\hline$d$ & $\mathrm{~b}^{5}$ & $\mathrm{~b}^{4}$ \\
\hline$e$ & $\mathrm{~b}^{1}$ & $\mathrm{~b}^{5}$ \\
\hline
\end{tabular}


As indicated in table II (the box indicates the correct tag), under tag corruption situation, the receiving algorithm can identify the tag at the second receiving cycle. Consider the situation of loosing the first four characters of the tag and the following indicates the identification process.

TABLE 11I

DATA IDENTIFICATION WHEN FOUR CHARACTERS ARE MISSING

\begin{tabular}{|c|c|c|c|c|c|}
\hline \multirow{2}{*}{$\begin{array}{c}\text { Assigned } \\
\text { Variable }\end{array}$} & \multicolumn{5}{|c|}{ Receiving cycle } \\
\cline { 2 - 6 } & 1 & 2 & 3 & 4 & 5 \\
\hline$a$ & $\mathrm{~b}^{5}$ & $\mathrm{~b}^{4}$ & $\mathrm{~b}^{3}$ & $\mathrm{~b}^{2}$ & $\mathrm{~b}^{1}$ \\
\hline$b$ & $\mathrm{~b}^{1}$ & $\mathrm{~b}^{5}$ & $\mathrm{~b}^{4}$ & $\mathrm{~b}^{3}$ & $\mathrm{~b}^{2}$ \\
\hline$c$ & $\mathrm{~b}^{1}$ & $\mathrm{~b}^{1}$ & $\mathrm{~b}^{5}$ & $\mathrm{~b}^{4}$ & $\mathrm{~b}^{3}$ \\
\hline$d$ & $\mathrm{~b}^{2}$ & $\mathrm{~b}^{1}$ & $\mathrm{~b}^{1}$ & $\mathrm{~b}^{5}$ & $\mathrm{~b}^{4}$ \\
\hline$e$ & $\mathrm{~b}^{3}$ & $\mathrm{~b}^{2}$ & $\mathrm{~b}^{1}$ & $\mathrm{~b}^{1}$ & $\mathrm{~b}^{5}$ \\
\hline
\end{tabular}

Still, the algorithm is able to recover the tag under worst distortion condition. Therefore, seven receiving cycles guarantee the correct identification of the tag under any tag corruption situation.

\section{INTELLIGENT VEHICLE INTERFACING}

Once the tag has been identified by the microcontroller, it is necessary to deliver the disabling signal to the intelligent vehicle control unit (see Fig. 10). The intelligent vehicle control system, basically handles the ignition system, automatic gear changing system, and vehicle power supply system. One of the key tasks of this interfacing is to disable the above functions of the vehicle intelligently to immobilize the vehicle on the road that is being hijacked.

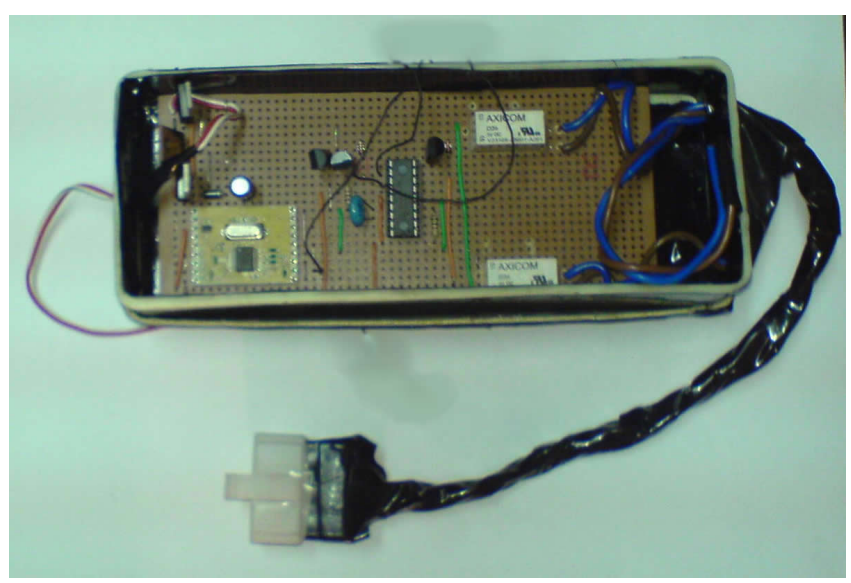

Fig, 9. Receiver and vehicle interfacing unit

Once the disabling signal is sent by the onboard receiver unit microcontroller, the intelligent control unit microcontroller will take into consideration the speed of the vehicle and delivers control signals to the above 3 subsystems (also see Fig. 10) to immobilize the vehicle within a safe distance from the place it was hijacked.

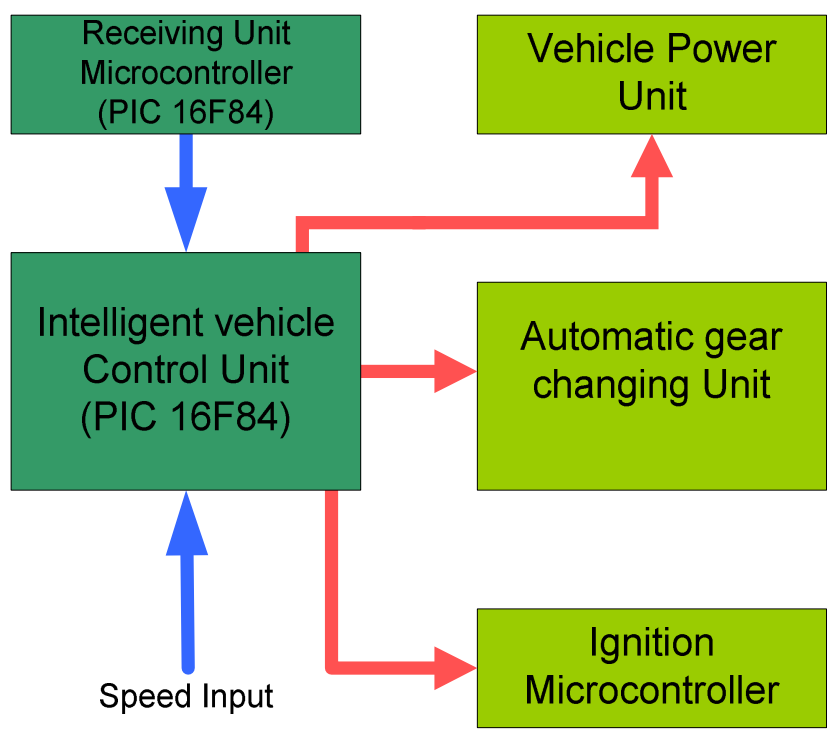

Fig. 10. Intelligent Vehicle Control System

The control command by the intelligent control unit will be realized based on the three different scenarios depending on the current speed of the vehicle. The main emphasis is on disabling the vehicle ignition system and further action will be taken if the speed continues to do so. This system guarantees that the vehicle is immobilized after a $1.0-1.5 \mathrm{~km}$ travel after the tag is identified by the receiving system. The control actions taken under different speed levels are summarized in table IV.

TABLE $1 \mathrm{~V}$

THE SPEED OF THE VEHICLE AND CONTROL ACTION

\begin{tabular}{|c|l|}
\hline $\begin{array}{c}\text { Speed } \\
\text { (km per hour })\end{array}$ & \multicolumn{1}{|c|}{ Control Action } \\
\hline $0-30$ & $\begin{array}{l}\text { Ignition system off / Neutral gear/ } \\
\text { Vehicle power off }\end{array}$ \\
\hline $30-60$ & Ignition system off / Neutral gear \\
\hline Above 60 & Ignition system off \\
\hline
\end{tabular}

\section{FIELD TEST RESULTS AND DISCUSSION}

Comprehensive field testing was carried out on the entire system under different environmental conditions and various possible signal distortion situations.

\section{A) Testing under different climatic conditions}

The immobilizer was experimentally tested on a vehicle under different weather conditions, namely, rainy, cloudy, windy, and bright weather conditions. Under those conditions, the operating distances were tested and the results are given in table $\mathrm{V}$. 
TABLE V

THE OPERATING DISTANCE IN DIFFERENT WEATHER CONDITIONS

\begin{tabular}{|c|c|}
\hline Weather condition & Operating distance $(\mathrm{m})$ \\
\hline rainy weather & 171 \\
\hline cloudy weather & 191 \\
\hline windy weather & 194 \\
\hline bright weather & 202 \\
\hline
\end{tabular}

Therefore, the system performs highly reliably under any weather condition within a range of $170-200 \mathrm{~m}$.

\section{B) Testing under different signal distortion conditions}

The system was tested under different signal distortion conditions to verify the data capturing capability and reliability. Therefore, the first tag was deliberately distorted and checked the capability of recognition of tag. The first tag sent was $b^{2} b^{3} b^{4} b^{1}$ and then correct tag was sent to the receiver unit. As table VI shows, the system guarantees its reliability by successfully recovering the code sent.

TABLE VI

DATA IDENTIFICATION UNDER FOUR CHARACTER MISSING

\begin{tabular}{|c|c|c|c|}
\hline \multirow{2}{*}{$\begin{array}{c}\text { Assigned } \\
\text { Variable }\end{array}$} & \multicolumn{3}{|c|}{ Receiving cycle } \\
\cline { 2 - 4 } & 1 & 2 & 3 \\
\hline$a$ & $\mathrm{~b}^{2}$ & $\mathrm{~b}^{2}$ & $\mathrm{~b}^{1}$ \\
\hline$b$ & $\mathrm{~b}^{3}$ & $\mathrm{~b}^{3}$ & $\mathrm{~b}^{2}$ \\
\hline$c$ & $\mathrm{~b}^{4}$ & $\mathrm{~b}^{4}$ & $\mathrm{~b}^{3}$ \\
\hline$d$ & $\mathrm{~b}^{1}$ & $\mathrm{~b}^{5}$ & $\mathrm{~b}^{4}$ \\
\hline$e$ & $\mathrm{~b}^{1}$ & $\mathrm{~b}^{1}$ & $\mathrm{~b}^{5}$ \\
\hline
\end{tabular}

\section{CONCLUSIONS}

The proposed security system has proved to be capable and reliable under hijacking situation without perceived damage to the passengers in the vehicle and driver. The relatively low hacking probability will lead vehicle hijackers to true ambiguity at a real world situation.
There is room for further development in the intelligent vehicle control part in particular as one can incorporate a suitable fuzzy expert system to make optimal decisions depending on the situational factors exist at the location and the nature of the incident. The testing of the complete system has also proved the reliability of the proposed system under different contingent situations. Therefore, the proposed anti-theft auto security system with an immobilizer provides safe and reliable solution for the ever increasing threat of vehicle hijackings around the world.

\section{ACKNOWLEDGMENT}

The authors sincerely thank Sri Lanka Inventors Commission (SLIC) for funding this project.

\section{REFERENCES}

[1] Rudy T. Sanders, Lee Fleishman., 1987. "User identifying vehicle control and security device", United States Patent 4754255, May 14, 1987

[2] Robert Bosch GmbH, 2001., "Device for protecting a motor vehicle against theft “, United States Patent 6856044. Nov 7, 2001

[3] Alfredo J. Berard, James L. Mentzer, David C. Nixon., 1994. "Cellular/GPS system for vehicle tracking “, United States Patent 5515043, : August 17, 1994

[4] Eliezer A. Sheffer, Marco J. Thompson.,1992. "Vehicle tracking system “, United States Patent 5218367, June 1, 1992

[5] Paul-Andre Roland Savoie, Andre Eric Boulay., 1996," Vehicle tracking system using cellular network", United States Patent 5895436, April 26, 1996

[6] Auto-Trac Inc., 1992. "Vehicle tracking and security system ", United States Patent 5223844. April 17, 1992

[7] Voice Control Systems Inc., 1998. "Speech controlled vehicle alarm system”, United States Patent 5706399. Jun 3, 1996.

[8] RF Solutions Ltd., 2004.” Dual Band FM Wireless Transceivers“, June 200404

[9] Landt, Jerry (2001). "Shrouds of Time: The history of RFID “. AIM, Inc. Retrieved on 2006-05-31.

[10] Li Zhekun, Rajit Gadh, B.S. Prabhu.,"Applications Of Rfid Technology And Smart Parts In Manufacturing", Proceedings of DETC'04:ASME 2004 Design Engineering Technical Conferences andComputers and Information in Engineering Conference., Salt Lake City, Utah USA ,September 28-October 2, 2004

[11] Lampe, M. and Strassner, M. (2003). The Potential of RFID for Moveable Asset Management. In Workshop on Ubiquitous Commerce at Ubicomp 2003.

[12] Dargan, Gaurav; Johnson,Brian; Panchalingam, Mukunthan; Stratis, Chris (2004). The Use of Radio Frequency Identification as a Replacement for Traditional Barcoding. Retrieved on 2006-05-31.

[13] RFID Journal (2003). "Can RFID Save the Cattle Industry?". Vertical Focus, December 23,2003. Available http://www.rfidjournal.com/article/articleview/1032 (22.5.2006).

[14] Auto-ID Center. $860 \mathrm{MHz}-960 \mathrm{MHz}$ class I radio frequency identification tag radiofrequency \& logical communication interface specification: Recommended standard, version 1.0.0. Technical report http://www.autoidcenter.org, Massachusetts Institute of Technology, MA, USA, November 2000 